Eciftorial

\title{
IVIG in Neonatal Sepsis: Alea iacta est?
}

\author{
Volker N Umlauf ${ }^{1}$, Christian Gille ${ }^{2}$, Thorsten W Orlikowsky ${ }^{1 *}$
}

*1Department of Neonatology, University Children's Hospital, 52074 Aachen, Germany

${ }^{2}$ Department of Neonatology, University Children's Hospital, 72076 Tuebingen, Germany

\section{Keywords: Neonate; Sepsis; Inflammation; IVIG}

With an incidence of $16 \%$ and a risk of mortality of $4 \%$ sepsis in preterm newborns with a birth weight $<1,500$ grams remains a burden problem. Despite antibiotic treatment, the incidence of sepsis stayed stable over the past decades in western industry nations, however there was a shift within the spectrum of pathogens from group B streptococci (GBS) to gram negative microbes. Preterm infants have decreased immunoglobulin concentrations below protective antibody titers; combined with their immature immune system they have an increased susceptibility for infections and sepsis [1]. Thus, therapy studies focus on adjunctive therapies such as immunoglobulins.

So far a multitude of smaller studies and three Cochrane systematic reviews, including nearly 6,000 patients, suggested positive effects on mortality by use of non-specific, polyclonal IVIg in proven or suspected sepsis of the preterm newborn $[2,3]$. Then, in September 2011, the International Neonatal Immunotherapy Study (INIS) Collaborative Group published their results of an international, placebo controlled, multicentre randomized trial on almost 3,500 preterm infants with a birth weight less than 1,500 grams [4]. They conclude unmistakable: "Therapy with intravenous immune globulin had no effect on the outcomes of suspected or proven neonatal sepsis". This statement is supported by a number of former and a recent invitro study [5] and a review [6] providing reasons for failure of IVIg due to inhibited immune system components by IVIg. However, IVIg are constituted in sepsis therapy of the adult $[7,8]$ and in preventing infections in primary immunodeficiencies with lack of IgG. So, what are the reasons for failure of IVIg in neonatal sepsis? Has the last word now been said in the story of in-vivo IVIg use in neonatal sepsis? Alea iacta est [9] (Has the die been cast)?

In an updated Cochrane meta-analysis of IVIg in neonates with suspected or subsequently proven infection Ohlsson [3] included 10 trials involving almost 500 infants. He found a significant reduction in mortality after neither of his three preceding Cochrane meta-analyses from 1998, 2001 and 2004 revealed a significant effect. He obviously limits his results which are only statistical nature: The variable and mostly poor methodological quality of the included studies invalidate the statistical effect. Major criticism levelled at these studies are: not placebo controlled or randomized; poor number of involved patients, resulting actually in no significance if using correct statistical tests; weak definition of sepsis; different types of IVIg (i.e. IgM-derived); and from studies outside western industry nations a large number of uncommon sepsis pathogens i.e. salmonella, staphylococcus aureus.

The 2011 INIS trial, so far the largest trial investigating IVIg in proven or suspected infection, included 3493 newborns with a birth weight $\leq 1,500$ grams from 9 countries worldwide [4]. Two third of the children had a gestational age of 30 weeks or less. Limitation of this study are weak definition criteria for inclusion ("receiving antibiotics for the treatment of ... serious infection" with or without evidence of positive culture) which allows different interpretations between study centers. Two groups (IVIg vs. placebo) were performed and subgroup analyses were conducted to 28 single variables (i.e. two or more subgroups for birth weight; gestational age at birth; sex; maternal
C-reactive protein levels; duration periods of membrane rupture; type of infection: early or late or after surgery onset; country). There were no significant differences for primary (death, disability until 2 years of age) and secondary outcome (i.e. episodes of sepsis) in all groups. The subgroup analyses included larger numbers of neonates than previous meta-analyses of all neonatal data, but subgroups were not mixed, meaning no statement could be given to a group of female preterms of 25 weeks gestational age with a birth weight $<750$ $\mathrm{g}$ from New Zealand, for example. If the subgroups were combined to meaningful categories, the numbers of were nevertheless lower (and still non-significant?).

An additional reason for previous controversial results might be the fact of different antibody levels in commercial IVIg which can differ in-between manufactures and even charges. At least the proportion of species specific antibodies distinguishes.

Polyvalent IVIg derived against specific pathogens such as group B streptococci were developed by immunizing plasma donors [10], which is a cumbersome procedure. Nevertheless, group B steptococcispecific antibody levels were fourfold higher and prolonged observed after admission compared to standard polyvalent IVIg. INH-A21 and Altastaph ${ }^{\circ}$, IVIg with high titers of antibody to Staphylococcus epidermidis and Staphylococcus aureus, respectively, failed to reduce the incidence of neonatal sepsis in preterm babies [11]. IgMenriched IVIg showed no benefit compared to standard IVIg [12]. Monoclonal antibodies ( $\mathrm{mAb}$ ) against type specific antigens of group b streptococci seem to be effective in experimental models of neonatal sepsis [13] as well as in-vivo (pagibaximab) against staphylococci [14]. Restrictively, those $\mathrm{mAb}$ are currently preventive. More pathogen specific and quicker diagnostic tests are necessary, i.e. real time PCR or molecular assays.

An explanation of failure of immunglobulins in preterms can be found in in-vitro studies, explaining the interactions of IVIg and an undeveloped immune system.

IgG concentrations below $4 \mathrm{~g} / \mathrm{l}$ are associated with an increased risk of infection in preterm infants [15]. Efficiency of transplacental transport of IgG is highly correlated to gestational age with the result of a decreasing deficient transfer with lower weeks' gestation [1] Besides, preterm infants have a limited ability of own immunoglobulin production. With loss of maternal IgG they rather fall into a longerlasting and more distinctive hypogammaglobulinemia than mature

*Corresponding author: Thorsten W. Orlikowsky, MD, Department of Neonatology University Children's Hospital,Pauwelsstr. 30, 52074 Aachen, Germany, Tel: +49 (0) 24180 89214; Fax: +49 (0) 24180 82437; E-mail: torlikowsky@ukaachen.de

Received January 11, 2012; Accepted January 13, 2012; Published January 16, 2012

Citation: Umlauf VN, Gille C, Orlikowsky TW (2012) IVIG in Neonatal Sepsis: Alea iacta est?. J Neonatal Bio 1:e102. doi:10.4172/2167-0897.1000e102

Copyright: (C) 2012 Umlauf VN et al. This is an open-access article distributed under the terms of the Creative Commons Attribution License, which permits unrestricted use, distribution, and reproduction in any medium, provided the original author and source are credited. 
newborns. It is for this reason a quite simple thought-circuit, making the lack of IgG (partly) responsible for the susceptibility to infection - and resolve that susceptibility by intravenous substitution of IgG. Commercial available IVIg have non-specific and in low concentrations a polyvalent spectrum of specific antibody components due to deriving IVIg form ten thousands of plasma donors.

IVIg is known to inhibit the production of circulating cytokines as one result of suppressing the activation of monocytes with an altering transcription of various inflammatory genes. Furthermore, IVIg inhibits proliferation of activated $\mathrm{B}$ and $\mathrm{T}$ lymphocytes and inflammatory activation via a diverse array of mechnisms. Gille et al. [5] found a down-modulation of the Fc $\gamma$ III-receptor (CD16) which is a major mediator of phagocytosis of opsonized microbes. Furthermore, an increase of bacterial load per monocyte, lower phagocytosis rates of group B streptococci and an inhibition of the up-regulation of CD80, CD86 and HLA-DR as well as a reduced $\mathrm{T}$ cell proliferation were shown in their in-vitro model of mononuclear cell culture, derived with polyvalent IVIg.

Thus, at present, the prefinal answers on "Alea iacta est?" has to be: The die has irrevocably cast regarding the use of polyvalent IVIg. Concerning a recommendation for therapeutic use of IVIg in neonatal sepsis there is nothing new to us since the mid of the 1990s: There is still no advise for the therapeutical application of IVIg in neonatal sepsis. The die has not finally cast relating species specific IVIg and $m A b$. Further trials with more specific antigens are needed. More pathogen specific diagnostic approaches might be helpful in this context.

\section{References}

1. van den Berg JP, Westerbeek EA, van der Klis F M., Berbers GA., van Elburg RM (2011) Transplacental transport of IgG antibodies to preterm infants: a review of the literature. Early Hum Dev 87: 67-72.

2. Ohlsson A, Lacy JB (2004) Intravenous immunoglobulin for preventing infection in preterm and/or low-birth-weight infants. Cochrane Database Syst Rev: CD000361.

3. Ohlsson A, Lacy J (2010) Intravenous immunoglobulin for suspected or subsequently proven infection in neonates. Cochrane Database Syst Rev: CD001239.

4. Brocklehurst P, Farrell B, King A, Juszczak E, Darlow B, et al. (2011) Treatment of neonatal sepsis with intravenous immune globulin. $\mathrm{N}$ Engl J Med 365: 1201-1211.

5. Gille C, Dreschers S, Spring B, Tárnok A, Bocsi J, et al. (2012) Differential modulation of cord blood and peripheral blood monocytes by intravenous immunoglobulin. Cytometry B Clin Cytom 82: 26-34.

6. Wynn JL, Seed PC, Cotten CM (2010) Does IVIg administration yield improved immune function in very premature neonates? J Perinatol 30: 635-642.

7. Kreymann KG, de Heer G, Nierhaus A, Kluge S (2007) Use of polyclona immunoglobulins as adjunctive therapy for sepsis or septic shock. Crit Care Med 35: 2677-2685.

8. Laupland KB, Kirkpatrick AW, Delaney A (2007) Polyclonal intravenous immunoglobulin for the treatment of severe sepsis and septic shock in critically ill adults: a systematic review and meta-analysis. Crit Care Med 35: 2686-2692.

9. Suetonius Tranquillus G (120 A.D. / 1973) De vita caesarum libri I - Divus Iulius. Teubner, Stutgardiae.

10. Fischer GW, Weisman LE, Hemming VG (1992) Directed immune globulin for the prevention or treatment of neonatal group B streptococcal infections: a review. Clin Immunol Immunopathol 62: S92-97.

11. Shah PS, Kaufman DA (2009) Antistaphylococcal immunoglobulins to prevent staphylococcal infection in very low birth weight infants. Cochrane Database Syst Rev: CD006449.

12. Haque KN, Remo C, Bahakim H (1995) Comparison of two types of intravenous immunoglobulins in the treatment of neonatal sepsis. Clin Exp Immunol 101: 328-333.

13. Hill HR, Kelsey DK, Gonzales LA, Raff HV (1992) Monoclonal antibodies in the therapy of experimental neonatal group B streptococcal disease. Clin Immunol Immunopathol 62: S87-91.

14. Weisman LE, Thackray HM, Steinhorn RH, Walsh WF, Lassiter HA, et al (2011) A randomized study of a monoclonal antibody (pagibaximab) to prevent staphylococcal sepsis. Pediatrics 128: 271-279.

15. Sandberg K (2000) Preterm infants with low immunoglobulin G levels have increased risk of neonatal sepsis but do not benefit from prophylactic immunoglobulin G. J Pediatr 137: 623-628. 